\title{
Entailment Issues to Integrate Learning Theories with Educational Technologies
}

\author{
David Prata, George França, and Marcelo Lisboa
}

\begin{abstract}
Learning technologies intrinsically pervade education via Internet, encouraging teachers to conform their pedagogical practices. However, this information era imposes an interdisciplinary and multidisciplinary approach for applying instructional strategies to technology. In this work, a knowledge engineering case is described to represent the knowledge design entailment issues when integrating learning theories with information technology. The systematic and procedural language of computers in scene illustrate the challenge task of instruction design to develop customized content and to assess students' learning. Underlying these reasons, this work create awareness for the long trip to deal with pedagogical technology intricate issues in order to cause students to learn, and not only to use technology tools.
\end{abstract}

Index Terms-Educational technology, knowledge engineering, pedagogical issues, instructional design, ontology.

\section{INTRODUCTION}

During the early years of this century, the concepts of network, cyberspace, and hypermedia, were consolidated as language. Directly, such elements have grounded new forms of work. Structures of companies and universities took shape according to this new global phenomenon. Establishing new parameters for a globalizing market drove by an emerging educational culture, and often idealized and shaped by capital doctrine.

Regarding all the historical and structural issues related to Education and Technology, the contemporary discussion earns another view: some models and traditional values in universities and educational institutions are getting obsolete. Similarly, the work styles, and even the understanding of knowledge production and technology processes acquire other senses.

In this context, we observe more closely the relationship between knowledge, technology, and teaching and learning. Especially in this primacy moment of hypermedia, globalization, and information. A major challenge for educators is to realize that learning relationships are beyond conventional classroom, but closer to individual experiences from the diversity of technological languages, also considering what we call social groups.

The educational technologies bring us strong impact on the way we perceive the educational process. Actually, we could now understand it is not only provide content and technology

Manuscript received February 5, 2015; revised April 22, 2015. This work was supported in part by the Funração Universidade Federal do Tocantins UFT, productive grant

The authors are with the Department of Computer Science of the Federal University of Tocantins, Brazil (e-mail: ddnprata@uft.edu.br). to students and teachers, as was thought earlier in the "industrial age".

Likewise, we realize that publishing only interfaces, authoring tools, and content does not exhaust the debate, since the progress or course of a development work involves a team composed of different professionals from different areas that complement each other, such as teachers, designers, writers, programmers and others, characterizing the need for interdisciplinarity to solve problems within these new paradigms [1].

This work has the purpose to illustrate the challenge task of instruction design to develop customized content and to assess students' learning. A knowledge engineering case is described to represent the knowledge design entailment issues when integrating learning theories with information technology.

Next section we present the cyberspace as a cultural language. In Section III, we present a case study where educational technology is applied, like ontology, to assess the cognitive domain of students. In Section IV, we discuss some entailment issues in implementing knowledge representation as technology language, an ontology base case. For Section V, we present the final remarks.

\section{CyBerspaCe LANGUAGE}

The cyberspace language deeply affected the forms of relationship and professionalism, and even the prospects of the world we live in.

The Internet culture is the culture of the Internet creators, a set of values and beliefs that forms the behavior. Representative patterns of behavior generate standards, which are repeated by institutions, as well as social and informal organizations [2].

In this scenario, not only in education, but also in its entire spatial dimension, the cyberspace has become a society language and culture in constant evolution and movement. The cyberspace values are continuously reaffirmed, assuming a world of operations, functions, and different meanings, lived, and experienced, by people. It is composed by a series of media, presenting a different personality, full of interactivity, paths and options. After all, it is compiled as a "mix" of languages, uniting various media that complement each other, supporting itself as a hybrid language.

In educational scope, the hypermedia and learning environments brought elements that can be facilitators for the learning process. In this scenario, the technological processes tend to optimize time, space and understanding of very complex issues. For this reason, learning environments are available in cyberspace and participates directly in this 
scenario, as well as a new language with its features.

Considering these points, we tension the importance of understanding the educational technologies learning environments and their uses, not merely as a demonstration of a technological apparatus, but as a way to assimilate and represent the new teaching and educational forms of today, which technologies and their contours present.

\section{INTEGRATING EDUCATIONAL TECHNOLOGIES AND LEARNING THEORIES: COGNITIVE AND AFFECTIVE ASSESSMENT CASE}

The movement of the information age has focused attention on critical thinking as an important way to succeed in life [3], [4]. Old patterns as the ability to perform a standardized test of basic skills remains appropriate, but today is not the only way to judge the success or failure of academic students. Learning, in its broadest sense involves socialization and affective aspects. The continuous and affective assessment allows teachers to better understand the performance of their students. By understanding the reasons (e.g., lack of motivation, low self-esteem) of low student performance, teachers are able to handle them more appropriately and customized to their reality.

Bloom produced a hierarchical cognitive taxonomy consisting of six successive levels: knowledge, understanding application, analysis, synthesis and evaluation. Current research in evaluating texts composition classify the composition of texts in the last two levels of Bloom's taxonomy [5]: synthesis and evaluation.

The synthesis refers to the ability to combine parts into a whole new set of abstract relationships. The assessment is the ability to judge values with a purpose, a rationally judge. To analyze and synthetize, the student needs to exercise critical thinking. Critical thinking is the ability to analyze facts, generate and organize ideas, defend opinions, make comparisons, draw inferences, evaluate arguments and solve problems [4].

Ref. [3] proposed a model for critical thinking considering affective and behavioral aspects in addiction to the cognitive, demonstrating the difficult to separate attitudes of cognitive processes. For the use of educational technologies, motivation (emotional) plays a fundamental role in learning due to the autonomy of the student [6].

Moreover, the assessment of students' behavior could be done through their interaction with their peers. The social learning theory suggests that people learn by watching other people in a social setting [7]. The social cognition studies the mental processes of highest order involved in social information (perception, memory, attention, reasoning and problem solving). Based on these evidences, we can suggest critical thinking related to social cognition and to affective domain.

The social cognition studies the individual within a social or cultural context and emphasizes how people perceive and interpret the information generated by themselves (intrapersonal) or by others (interpersonal) [8]. Reflecting the importance of the text within the historical, social and cultural context [9], the student interacts with peers in the composition and discussion of texts, internalizing concepts in a perspective of meaning negotiation.

The affective domain [10] consists of behaviors such as perception of attitudes and awareness, interest, attention, consideration, responsibility, ability to listen and respond in interactions with peers; in addition to the ability in demonstrating these characteristics of posture or values in an appropriate manner to the situation or field study.

TABLE I: ASSESSMENT OF COGNITIVE DOMAIN By TECHNOLOGICAL

\begin{tabular}{|l|l|l|}
\hline \multicolumn{3}{|c|}{$\begin{array}{l}\text { Conceptual } \\
\text { Analysis }\end{array}$} \\
\hline $\begin{array}{l}\text { Remembering } \\
\text { concepts }\end{array}$ & Using concepts & $\begin{array}{l}\text { Statistical analysis of } \\
\text { the terms used and } \\
\text { description of objects } \\
\text { and entities }\end{array}$ \\
\hline $\begin{array}{l}\text { Understanding } \\
\text { concept meaning }\end{array}$ & $\begin{array}{l}\text { Explain concepts } \\
\text { with own words }\end{array}$ & $\begin{array}{l}\text { Natural Language } \\
\text { Processing }\end{array}$ \\
\hline $\begin{array}{l}\text { Applying acquired } \\
\text { concept in new } \\
\text { situations }\end{array}$ & $\begin{array}{l}\text { Solving problems in } \\
\text { new situations }\end{array}$ & $\begin{array}{l}\text { Semantic analysis } \\
\text { supported by ontology: } \\
\text { terms, objects, and } \\
\text { instances }\end{array}$ \\
\hline $\begin{array}{l}\text { Separation of } \\
\text { concepts in an } \\
\text { organized structure } \\
\text { of component parts }\end{array}$ & $\begin{array}{l}\text { Make inferences and } \\
\text { find evidence to } \\
\text { support } \\
\text { generalizations }\end{array}$ & $\begin{array}{l}\text { Semantic analysis } \\
\text { supported by ontology }\end{array}$ \\
\hline $\begin{array}{l}\text { Building a structure } \\
\text { from diverse } \\
\text { elements }\end{array}$ & $\begin{array}{l}\text { To summarize. } \\
\text { induction }\end{array}$ & $\begin{array}{l}\text { Creation of ontologies. } \\
\text { Semantic analysis } \\
\text { based on ontology }\end{array}$ \\
\hline $\begin{array}{l}\text { Evaluation of ideas } \\
\text { and materials }\end{array}$ & $\begin{array}{l}\text { Realize a critical } \\
\text { analysis. } \\
\text { Contextualize }\end{array}$ & $\begin{array}{l}\text { Semantic analysis by } \\
\text { NLP and Artificial } \\
\text { Intelligence of the } \\
\text { students interactions in } \\
\text { text dialog }\end{array}$ \\
\hline
\end{tabular}

TABLE II: ASSESSMENT OF AFFECTIVE DOMAIN

\begin{tabular}{|l|l|l|}
\hline \multicolumn{3}{|c|}{ Level } \\
\begin{tabular}{|l} 
Awareness, \\
willingness to listen, \\
attention
\end{tabular} & $\begin{array}{l}\text { Listening to others with } \\
\text { consideration }\end{array}$ & $\begin{array}{l}\text { Statistical analysis } \\
\text { of texts and } \\
\text { comments of the } \\
\text { discussions }\end{array}$ \\
\hline $\begin{array}{l}\text { Active participation } \\
\text { by the learner. }\end{array}$ & $\begin{array}{l}\text { Participating in the } \\
\text { discussion. Questioning } \\
\text { new concepts to learn } \\
\text { them. Knowing and } \\
\text { responding to a } \\
\text { particular } \\
\text { phenomenon }\end{array}$ & $\begin{array}{l}\text { Statistical analysis } \\
\text { of participation in } \\
\text { the debates and in } \\
\text { composition of texts }\end{array}$ \\
\hline $\begin{array}{l}\text { Valuation to an } \\
\text { object, phenomenon } \\
\text { or particular } \\
\text { behavior }\end{array}$ & $\begin{array}{l}\text { Ability to solve } \\
\text { problems and propose } \\
\text { solutions }\end{array}$ & $\begin{array}{l}\text { Statistical analysis } \\
\text { of the depth } \\
\text { discussions }\end{array}$ \\
\hline $\begin{array}{l}\text { Organization of } \\
\text { values in priorities, } \\
\text { comparing and } \\
\text { synthesizing }\end{array}$ & $\begin{array}{l}\text { Ability to } \\
\text { systematically specify } \\
\text { problems and proposed } \\
\text { solutions }\end{array}$ & $\begin{array}{l}\text { Statistical analysis } \\
\text { of the debates } \\
\text { (answers and } \\
\text { concordances) }\end{array}$ \\
\hline $\begin{array}{l}\text { Internalizing values. } \\
\text { Setting general } \\
\text { standards in } \\
\text { personal, social and } \\
\text { emotional behavior }\end{array}$ & $\begin{array}{l}\text { Review judgments and } \\
\text { changes in behavior }\end{array}$ & $\begin{array}{l}\text { Statistical and } \\
\text { semantic analysis of } \\
\text { the debates } \\
\text { (disagreement and } \\
\text { agreement) and } \\
\text { composition }\end{array}$ \\
\hline
\end{tabular}

This domain may be better exploited with the use of interpersonal interactive tools, providing evidence of student behavior. Teachers usually ponder this domain nature when making subjective assessment of their students (e.g. evaluation of the composition of texts). Monitoring the way of "how" the composed text was constructed by the student should support to mitigate the issue of human assessors in agreement among themselves about their concepts to the subjective assessment. 
We can assess the cognitive and affective domain using educational technologies in the following way, for example (Table I, Table II) [11].

\section{TECHNOLOGY IMPLEMENTATION ENTAILMENT ISSUES: ONTOLOGY CASE (TAXONOMY)}

\section{A. Knowledge Representation}

The use of diagrams in education is not new. There are some tools available and the community developed intense research in the 90s. The benefits of using these forms of knowledge representation are justified in the literature [12] [13].

For centuries, the philosophical ontology community has discussed how the nature of the world should be conceptualized. When the computing community began structuring and systematizatizing knowledge bases, these problems emerged again. Nowadays, with the extreme growth of information, thanks to the Internet and the emergence of new fields of science such as nanotechnology, information technology could not handle this huge amount of knowledge only with rules-based systems. This knowledge has to be categorized in some way to allow the rules make sense in a lower context. In the following sections, we discuss the knowledge categorization of problems in the form of taxonomy in order to study the impact of various diagrammatic epistemology ways to classify knowledge.

\section{B. Different Organization X Different Meaning}

Assuming an array of characters such as "A", "C", "H", "R". Depending on how these characters are organized, the meaning of their joint could change (Fig. 1).
$\mathrm{C}$

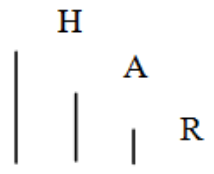

A

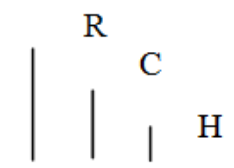

Fig. 1. Two identical arrays structure, with differently arrangements of characters, implying different meanings.

In biology, the work on autopoiesis [14] concluded that organisms are determined by their organization and structure. The system structure is changed when receiving environmental disturbances. The system's structure designs the interactions between interconnected components without changing the organization. The organization defines the system's properties showing how it is configured. A change in the organization implies a change for the system's purposes.

Comparing the theory of autopoiesis with knowledge engineering, we could observe similarities between the interconnection of components (structure) from organisms with instance relationships. In addition, we could perceive resemblances between the organization of the body and conceptual taxonomy. For example, in Fig. 2 and Fig. 3 [11], we have two conceptualizations of knowledge, making use of the same concepts, and their iconic representations based on their organization. It is noteworthy that a change in conceptual taxonomy results in a change on the meaning of the objects represented; i.e., a change for the purpose in which the system was designed. For instance, under the architectural approach, Fig. 2 represents an abstract bridge, and Fig. 3 an abstract obelisk. In another case, only changing the instance level do not affect the system's purposes. Even though Fig. 2a) and Fig. 2b) had their blocks changed for their instance level, the two figures continue to represent the same abstract bridge.

a)
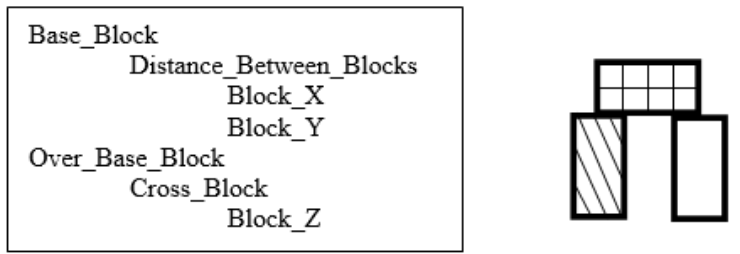

b)

$$
\begin{gathered}
\text { Base_Block } \\
\text { Distance_Between_Blocks } \\
\text { Block_X } \\
\text { Block_Z } \\
\text { Over_Base_Block } \\
\text { Cross_Block } \\
\text { Block_Y }
\end{gathered}
$$

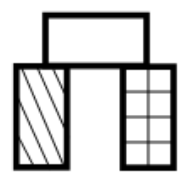

Fig. 2. Conceptualization and iconic representation, the bridge.
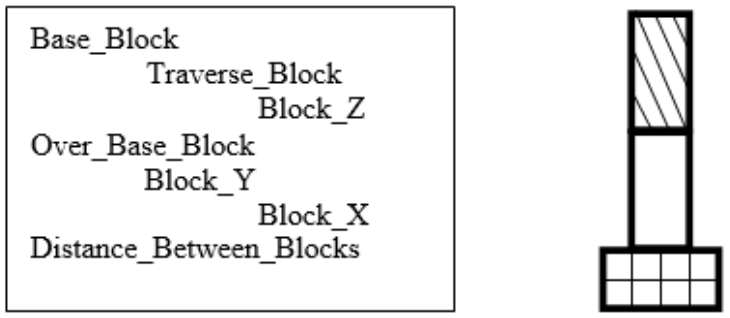

Fig. 3. Conceptualization and iconic representation, the obelisk.

Hence, for example, the relationship change between blocks X, Y, and Z, should not affect the purpose of the system. For the arch, changes in the structure of instance level, Fig. 2a) and Fig. 2b), do not modify the architectural meaning of the arch. The same proposition is also valid for the obelisk.

\section{Different Concepts Levels X Different Meanings}

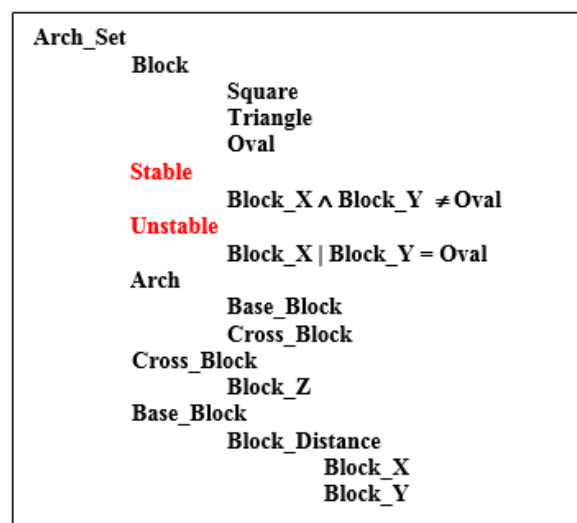

Fig. 4. Conceptualization of an arch set with the stability concept in the same hierarchical level than the block concept.

The next case deals with the meaning of a conceptualization when the taxonomy undergoes changes in their hierarchical level. A simplified illustrative scene is presented with the world of blocks [15]. The frame of reference is the presence of an arch between blocks.

Two possible descriptions of the concept of an arch assembly is shown in Fig. 4 and Fig. 5 [11]. In Fig. 4, there is a description of the arch concept for the stability concept 
located in the same hierarchical level of the block concept. For Fig. 5, the concept of stability is located under the hierarchical level of the block concept.

Observing the description of Fig. 6 [11], it defines clearly the blocks' stability. The square and the triangle inherit the stable concept of the hierarchy, while the oval inherits the unstable concept.

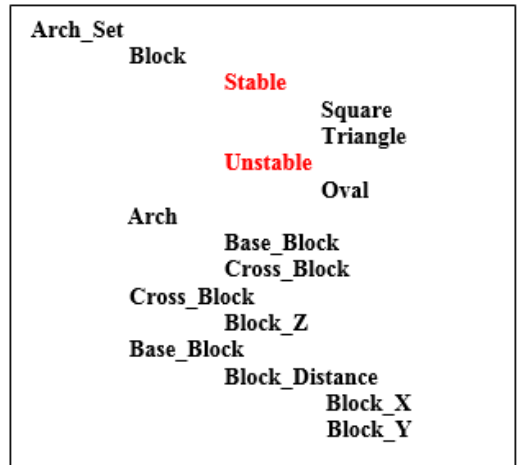

Fig. 5. Conceptualization of an arch set with the stability concept under the hierarchical level of block concept.

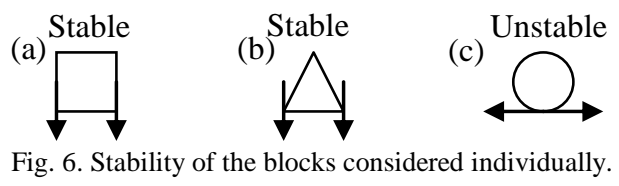

\section{Stability Concept Interpretation}

The descriptions of Fig. 4 and Fig. 5 define an arch by the concept of a block. An arch has two block bases, a cross block over the block bases and a distance between the block bases. The axiomatic relationships of Fig. 4 and Fig. 5 define the presence or absence of stability in the arch set. According to the taxonomic hierarchy of Fig. 4, it can be inferred: Stable_Arch_Set, or Unstable_Arch_Set. Moreover, the description of Fig. 5, according to the taxonomic hierarchy, infers Stable_Block, and Unstable_Block.

In the following cases, the conceptualizations of Fig. 4 and 5 are analyzed by means of to the arch set of Fig. 7 [11].

Fig. 7. Example of two base blocks with an over cross block, the arch concept.

\section{1) Case Fig. 7a)}

This figure is positively interpreted as stable by both conceptualizations, Fig. 4 and Fig. 5.

\section{2) Case Fig. 7b)}

According to the conceptualization of Fig. 4, the stability set depends on the condition of the oval block be or not to be a base block. For example, we can change the axiom "Block_X $\wedge$ Block_Y $\neq$ Oval" to "Base_Block $\neq$ Oval", and the conceptualization infers the same way. Likewise, axiom "Block_X | Block_Y = Oval" can be modified to "Base Block contains Oval".

In this case, according with the stability condition of Fig. 4, Fig. $7 b$ ) is consistent with the stability concept of the axiom.
However, according with the conceptualization of Fig. 5, Fig. $7 b$ ) has an oval block and thus is unstable. There is an unlike inference between the concepts of stability from these two conceptualizations, Fig. 4 and Fig. 5. The conceptualization of Fig. 5 does not reflect the concept of arch stability as a whole, because it considers the stability of the blocks taken separately. The blocks being considered as a set in Fig. 7b) should result the set as stable, even though there is an oval among them; because the distance between the base blocks steady the oval, leaving the building stable.

The scene analysis illustrates the systemic approach from [16]'s work, where the system's whole behavior has properties which the sum of its parts does not commit. For this case, despite of an oval block be part of the arch_set, the arch_set is stable.

Therewith, we could observe that the location of the concept of stability at different hierarchical levels from their conceptualization produces distinct concepts denotations. In other words, the meaning of the concept varies depending on its location in the hierarchical conceptualization.

\section{CONCLUSION}

In this work, we demonstrate artificial intelligence (AI) techniques to create and assess learning, like knowledge engineering. We could illustrate methods to approach the cognitive and affective domains of learning using technology.

Despite the feasible use of technology in education, our fine depict of AI techniques has the purpose to awareness the educational technology community about the intricate entailment issues, e.g., in modeling knowledge to develop technology tools.

In this work, it is worthwhile the pedagogical foundations, which orient the development processes for educational. Although, like Internet culture is the culture of the Internet creators, Educational Technology tools tends to image the thinking of their creators. We have in mind that an effective use of information technology in a more comprehensive understanding issue for learning corresponds to the need of students to learn, in a deeper and broadest sense, the technology language. Through the notion of computer's language, learners can explore and produce their own understanding. For instance, constructivists think knowledge as constructed by learners, making sense of their experience. Otherwise, we can suggest that the simple use of technology tools by students put them at risk in modeling their minds as the mind of the creators of the software. Moreover, even learners using technology in its broader view, the society is threatened to be embedded in a collective systematic and procedural mindset.

\section{ACKNOWLEDGMENT}

We would like to thank professor Patrick Letouze for his support and invaluable contributions.

\section{REFERENCES}

[1] G. França, "Os ambientes de aprendizagem na época da hipermídia e da educação a distância," Perspectivas em Ciência da Informação, vol. 14, pp. 1-14, 2009. 
[2] M. Castells, The Internet Galaxy. Reflections on the Internet, Business, and Society, Oxford: Oxford University Press, 2003, p. 7.

[3] W. Huitt, "Critical thinking: Why and when," presented at the Critical Thinking Conference sponsored by Gordon College, Barnesville, GA. Indiana University, 1998.

[4] G. Thomas and G. Smoot. (February/March 1994). Critical thinking: A vital work skill. Trust for Educational Leadership. [Online]. 23. pp. 34-38. Available: http://webapp1.dlib.indiana.edu/virtual_disk_library/index.cgi/42733 55/FID1736/journals/enc2315/2315.htm

[5] V. Neri and Cuchiarelli, "An overview of current research on automated essay grading," Journal of Information Technology Education, vol. 2, 2003.

[6] H. Noriko and R. Kling. (1999). Students' frustrations with a web-based distance education course: A taboo topic in the discours. Center for Social Informatics. [Online]. Available: http://www.slis.indiana.edu/CSI/papers.html.

[7] S. B. Merriam and R. S. Caffarella, Learning in Adulthood, (2ed.), San Francisco: Jossey-Bass, 1999.

[8] R. J. Sternberg and I. Q. Beyond, A Triarchic Theory of Human Intelligence, Cambridge, MA: Cambridge University Press, 1985.

[9] P. Freire, Educação Como práTica da Liberdade, 1983.

[10] B. S. Bloom, M. D. Engelhart, E. J. Furst, W. H. Hill, and D. R. Krathwohl, Taxonomy of Educational Objectives, The Classification of Educational Goals, New York, Longmans, 1956.

[11] D. N. Prata, Modelo de Análise de Conflitos em Diálogos em Aprendizagem Colaborativa (Analytical Model of Conflicts in Collaborative Learning Dialogues), Campina Grande, Brazil, 2008.

[12] D. Jonassen, Task Analysis Methods for Instructional Design, Lawrence Erlbaum Associates, 1999.

[13] J. D. Novak, "Concept mapping: A strategy for organizing knowledge, learning science in the schools: Research reforming practice," Lawrence Erlbaum Associates, Mahwah, pp. 229-245, 1995.

[14] F. Maturana and J. Varela, Autopoiesis and Cognition; The Organization of the Living, Boston: Reidel, 1980.

[15] M. Minsky, The Society of Mind, New York: Simon and Schuster, 1986.

[16] L. V. Bertalanffy, General System Theory, New York: George Braziller, 1968.

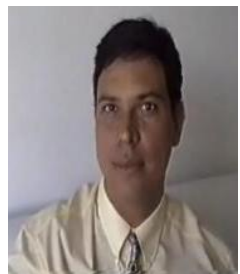

David Prata was born in Goiânia, Brazil on 18th September, 1965. Dr. Prata completed his bachelor of computer science in 1992. Then on, he went to complete his specializing in Academician. He worked as a system analyst to Tocantins Government, being in charge for the accountability and financial systems. Later, he successfully completed his master degree in computer science from Campina Grande
Federal University, with application research in education in 2000 year. He coordinates graduate and undergraduate courses in computer science at Alagoas Faculty in Maceio, Brazil. He was allotted to Federal University of Alagoas in 2006. Then, he moved to Federal University of Tocantins. His doctoral was developed in part at Carnegie Mellon University, USA completed in 2008 . He is currently coordinating a master degree in computational model. His research interests are education and ecosystems.

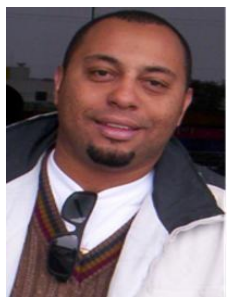

George França is a pprofessor at the Federal University of Tocantins UFT in the course of pedagogy and in the program of postgraduate in computational systems modeling. He got the doctor of education from Pontifical Catholic University of São Paulo. He graduated in philosophy at the Federa University of Santa Catarina - UFSC. He obtained the master in production engineering and systems: Media and knowledge from UFSC. He develops teaching, research and extension activities in the field of educational technology, distance education and philosophy of education. He is currently the pro-chancellor of extension and culture of the Federal University of Tocantins UFT.

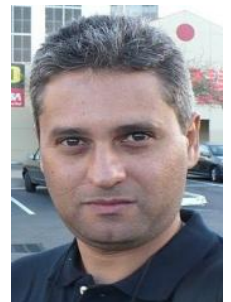

Marcelo Lisboa holds a degree in computer science from the Catholic University of Petrópolis (1994), the masters in computer from Fluminense Federal University (1997), the master science in electrical engineering from the Federal University of Rio de Janeiro (1999) and the Ph.D. in electrical engineering from the Federal University of Rio January (2008). He is currently a reviewer of the journal INFOCOMP,

Journal of Computer Science, and an associate professor from Federal University of Tocantins. He has experience in the area of computer science, mainly in the following topics of metaheuristics, combinatorial optimization, mathematical programming, computer networking and high performance computing teaching, research and extension activities in the field of educational technology, distance education and philosophy of education. He is currently the pro-chancellor of extension and culture of the Federal University of Tocantins UFT. 